\title{
Analysis and Improvement of the Suction Performance of Axial Piston Pumps in Swash Plate Design
}

\author{
Norman Bügener, Jan Klecker* and Jürgen Weber \\ Technical University Dresden, Institute of Fluid Power (IFD), Helmholtzstraße 7a, 01069 Dresden, Germany.
}

(Received 24 June 2014)

\begin{abstract}
The article illustrates a systematic investigation of the suction performance of hydrostatic pumps on the example of an axial piston pump in swash plate design. The focus is on pressure losses in the suction duct as well as on losses due to the interaction between the suction flow and the rotating group. The investigations of the suction flow are performed by means of numerical and experimental methods. Also a full cavitation model and a two-way fluid-structure-interaction approach were introduced for the numerical works. The experimental works were used to validate the CFD model. For the improvement of the suction performance two approaches are pursued. The bionic design of the suction duct based on meandering rivers and the suction pressure pulsation reduction by the help of a Helmholtz resonator. As a result of the CFD analysis, regions with the largest total pressure losses were identified. Based on CFD simulation significant improvements of the suction performance were shown due to the two presented measures. By means of the meander shape design the pressure losses reduced by more than $50 \%$ and the pressure ripple was dampened by about $9.5 \mathrm{~dB}$ using the integrated Helmholtz resonator.
\end{abstract}

Keywords: axial piston pump; FSI; viscoelastic; cavitation; bionic; Helmholtz resonator

\section{Introduction}

Axial piston pumps in swash plate design are one of the key components in fluid power applications as they can handle variable large flow volumes at high pressure levels. The field of piston pump applications shows a growing demand to further increase the power and speed of the pumps. Based on the continuous development of speed-variable pump drives with standard speed ranges of electrical servo motors, the application limits are to be extended. The limiting rotational speed, as labeled by the pump manufacturers, is based on valid steady-state flow velocities in the suction line of the piston pump. These empirically determined values include only the average static suction pressure. Complex transient processes, e.g. the flow oscillations, are ignored. In practise it can be observed that in spite of compliance of the speed and suction pressure limits given by the manufacturers a fault-free continuous operation is not guaranteed. Pump damages due to cavitation are not excluded. A further increase in speed is mainly in conflict with the initiation of gas cavitation on the suction side of the pump and leads to an increasing gas volume fraction. This causes the displacement chambers to be filled incompletely. If the critical speed is exceeded, the correlation between the flow rate and the speed becomes non-linear, see Fig. 1. The volumetric efficiency decreases. This also results in an increase of noise and leads to a shorter life cycle.

Knowledge of the coupled mechanisms and the dominating losses on the suction side enables a target-oriented improvement of the suction performance and therefore the widening of the operation range especially regarding higher pump speeds.

Besides major losses within the suction duct and losses because of the interaction between the suction flow and the rotating group the suction flow is investigated. On this basis, an aimed development of improvement measures takes place.

A new design of the suction duct following the shape of meandering rivers is a bionic approach to reduce the pressure losses from the pump inlet up to the rotating group. Such an approach was used by Rechenberg (1973) and Küppers (2006) in the development of „bionic pipe elbows”. Meandering rivers serve as a model for the design of the pipe elbows, which allow for a significantly more energy-efficient flow deflection than conventional pipe elbows with constant bending radius.

The inlet flow on the suction side of axial piston pumps also incorporate a $90^{\circ}$-turn, which leads to pressure losses. Thus, the development of a low-loss suction duct following the shape of meandering rivers seems like a logical step.

The biggest challenge of the transfer of the meander shape to the suction duct is its complex flow geometry compared to simply pipe elbows. Both a strong deflection and a shape adaption from circular to kidney-shaped have to be realised without enlarging the space requirement of the suction duct significantly and keeping the areas for the pump inlet and the suction kidney constant. 


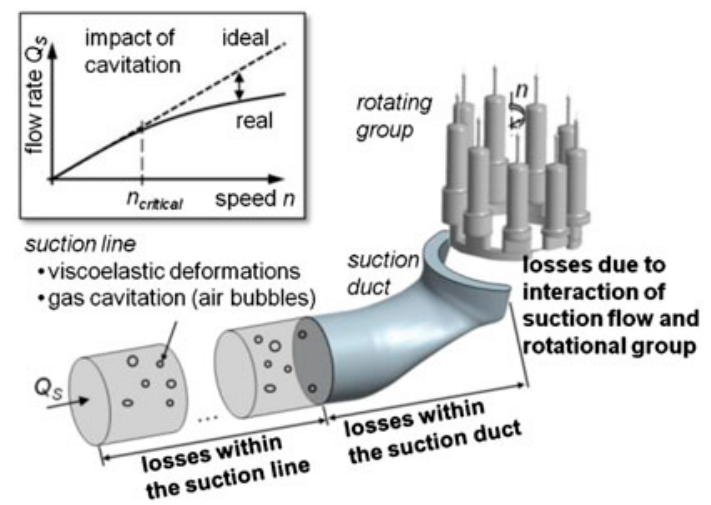

Figure 1. Influence of cavitation on the flow rate $\mathrm{Q}_{\mathrm{S}}$ with increase of speed $\mathrm{n}$ and main losses in the viscoelastic suction line.

To decrease the pressure pulsation in the suction duct a Helmholtz resonator (HR) is investigated regarding its suitability for an application on the suction side of hydrostatic pumps. A HR is a passive, secondary measure for the reduction of pulsations and is based on the interference principle. By contrast to absorption dampers, which convert acoustic energy to heat by using friction, reflection dampers reduce the primary sound wave by superposition with a secondary wave. Helmholtz resonators belong to the group of junction resonators, which in contrast to serial resonators are not flown through by the main stream of the fluid. For the technical-economical reasonable application in hydrostatic displacement units, a couple of boundary conditions are to be observed:

- simple design,

- low pressure losses,

- no secondary energy required,

- small installation space and low weight

- no maintenance required

- low costs

- application in a wide operational range

- no deterioration of the pump features (efficiency, noise, etc.).

Helmholtz resonators meet these requirements. Moreover, they have a good resistance against temperature, pressure and the used fluid.

The application to decrease the pressure pulsation on the suction side of hydrostatic pumps is not known. Thereby the challenges, compared to the high-pressure side, are the high compressibility of the fluid resulting from the low-pressure level, the high amount of free air and the low stiffness of the mainly used suction hoses. The bulk modulus of the oil-air mixture as well as the speed of sound highly depends on the air volume fraction. This uncertainty factor has to be considered at the design and the application of the resonator. On basis of numerical and experimental analyses of a damper prototype the development of an integrated design is carried out.
The goal of the present work is to reduce the major losses in the suction duct of an axial piston pump. With the help of computational fluid dynamics using new approaches for FSI and gas cavitation two original measures were analysed. The meander shaped duct design and the first time integrated Helmholtz resonator show significant improvements as well as a large potential for industrial applications.

\section{Suction Performance Of Axial Piston Pumps}

The total losses in the suction process of axial piston pumps consists of losses within the suction line and the suction duct as well as losses during the entry of the suction flow into the rotating group, see Fig. 1 (Bügener, 2014).

Today the design of the suction line of hydrostatic pumps is based on simple analytical approaches. Findeisen (2006) quotes limits for dimensioning, which have to be complied with in order to ensure that an average flow velocity $w_{S}=0,8 \mathrm{~m} / \mathrm{s}$ is not exceeded and the absolute suction pressure does not fall under $p_{S}=0,6 \ldots$ 0,8 bar (abs).

In order to improve the understanding of the meachnisms acting in the suction port and therefore forming a better foundation for improving the suction performance, simulation with lumped parameters (Casoli et al., 2006) and computational fluid dynamics (CFD) were used more intensively in the recent years (Wustmann, 2010 and Schleihs et al., 2014).

Wustmann (2010) used CFD to investigate the suction flow in an axial piston pump. Using pressure measurements and flow visualizations this approach was validated. Wustmann's investigations assumed an ideal and stiff suction line. A cavitation model was superimposed which designed with the vapour cavitation in mind. The gas cavitation that is dominant in the suction process was mainly accounted by a nonphysical parameterization of the model. The work that is presented in this paper adds an extension for elastic or viscoelastic behaviour of the suction line as well as an holistic cavitation model (only section 4).

The losses that are due to the flow diversion in the suction line, and the interaction between the suction flow and the rotating group, can be estimated using an analytical approach introduced by Kunze (1995), which is based on the streamline theory. However detailed statements can not be made, since the one dimensional approach introduces several assumptions. With the help of CFD, the occuring losses will be analysed in detail in the following section.

\section{Analysis Of The Suction Duct And The Rotating Group}

\subsection{CFD Models}

Figure 2 shows the CFD models for the steady-state investigations for two different pumps. 


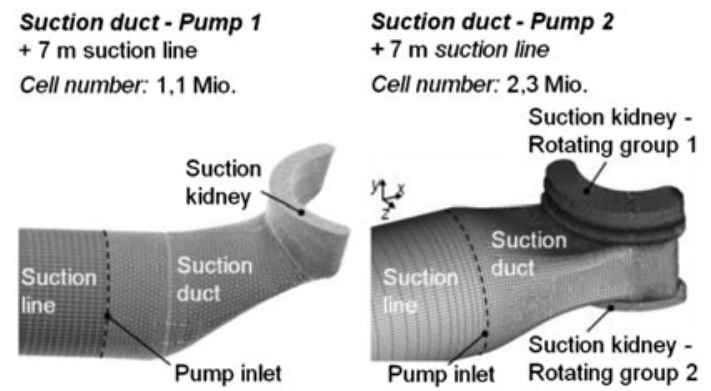

Figure 2. CFD models of the suction ducts of a single and a double pump for steady-state simulation.

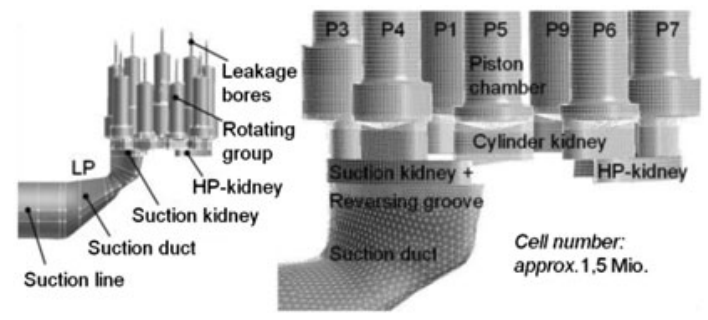

Figure 3. CFD model of pump 1 with the rotating group using dynamic mesh.

The suction duct of pump 1 is a simplification of the real geometry and neglects geometry details, e.g. chamfers. In order to analyse the losses of a real geometry the meshing of the suction duct of pump 2 was carried out under consideration of all production-caused details. Hence results in a total of $2.3 \times 10^{6}$ cells.

For the analysis of the suction performance under real pump behaviour, a transient simulation model of an axial piston pump with a dynamic mesh is being used. Figure 3 shows the CFD model of the 9 piston rotating group with a suction line.

The two displacement chambers P1/P6 consist of a much larger cell number than the remaining chambers, since these are used for the reversing processes between the high and low pressure side in the bottom (BDC) and top (TDC) dead centre region. Due to the higher flow gradients a larger cell resolution is necessary. The high pressure side of the pump is not in the main focus and was therefore reduced to a minimum cell count, which leads to an improvement of simulation time. For the boundary conditions of the flow regime, constant pressure conditions were chosen for the inlet and outlet of high pressure kidney, as well as for the leakage line of the slippers. More details of the mesh setup can be found in Bügener (2013).

All CFD models include a $7 \mathrm{~m}$ suction line to ensure a sufficiently long run-in distance to build up a fully developed velocity profile. Moreover the long suction line avoids the superposition of reflected pressure waves with the suction pressure pulsation during the simulation time. CFD computations were performed with a third of revolution of the rotating group.
For the fluid a compressible single-phase model was used, which is based on the pressure dependent effective bulk modulus of the oil-air-mixture considering the noncondensable gas volume fraction. Reynolds numbers in magnitudes in excess of 4000 were calculated for the flow of the analysed suction ducts. Therefore laminar-turbulent transition can be assumed. In this case the SSTmodel, which is used to calculate turbulences based on a combination of standard- $k$ - $\varepsilon$ - und $k$ - $\omega$-model, was chosen (Bügener, 2014). The CFD simulations presented in this paper were performed with the commercial code ANSYS $^{\circledR}$ CFX version 13 .

\subsection{Analysis of the Suction Duct}

Due its complex flow geometry several sources of losses can be found along side the flow path, beginning at the pump inlet through the suction kidney in towards the rotating group. The most important ones are listed schematically in Fig. 4.

The challenge is to guide the flow without any major losses from pump inlet to the rotating group. On the one hand, one has to deal with the reduction of the hydraulic diameter, and on the other with the shape change from circular to kidney-shaped. The diameter reduction leads to higher shear rates, which causes higher frictional losses.

However, the major losses that are resulting from directional changes of the flow and shape changes of the flow path are fundamentally more important than the minor losses. The losses due to the flow deflection are visualized in a cross section of pump 2 in Fig. 5.

The flow is not able to follow the sharp turn of the duct, which leads to flow separation and the formation of turbulences in a dead spot. The continuing energy dissipation in such a turbulence region is the major source of pressure losses. Additionally the boundary layer is being moved into the flow region, which leads to a reduced flow cross section and therefore to a rise in flow velocity. This leads to an increase in viscous losses.

A similar problem is found in areas with sudden changes to the hydraulic diameter, for example in manufacture related steps and groves. Here the flow is again not able to follow the shape, which leads to a stall and local pressure losses.

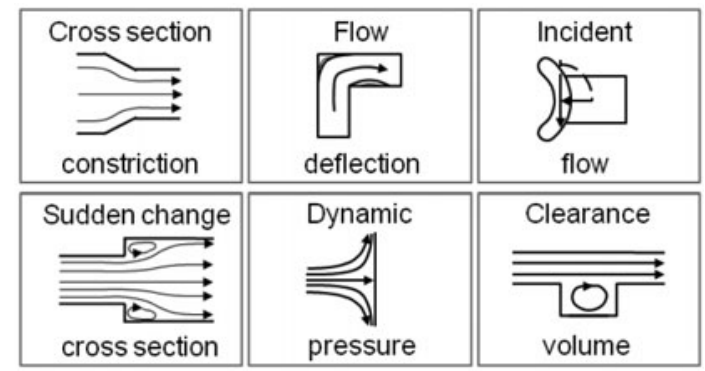

Figure 4. Causes for pressure losses in the suction duct. 


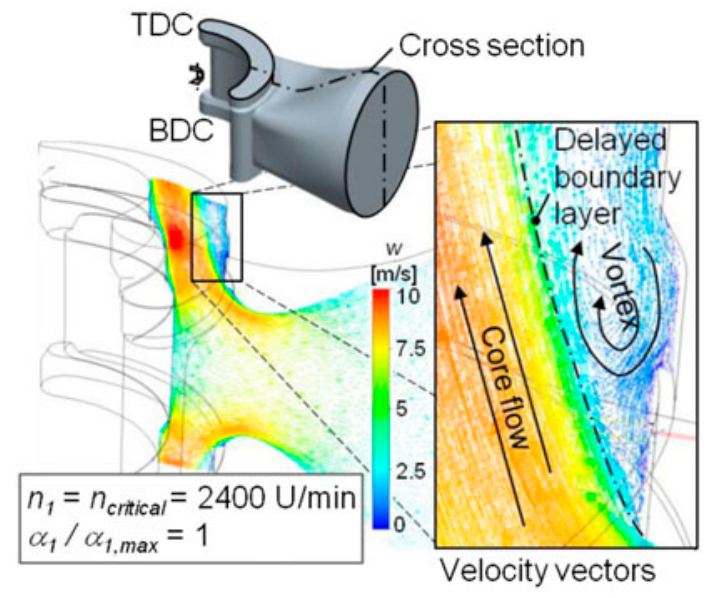

Figure 5. Flow separation at flow deflection.

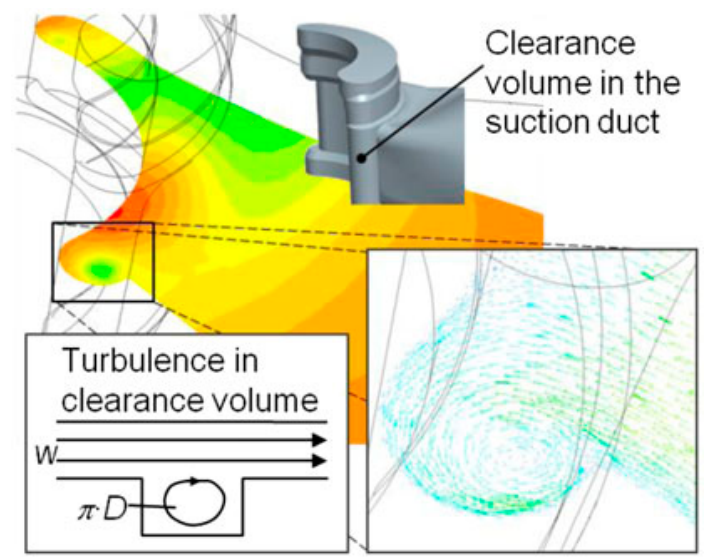

Figure 6. Turbulence in clearance volume.

The given suction port geometry of pump 2 shows a clearance volume limited by the manufacturing process. As shown in Fig. 6, this clearance volume is the source of a distinctive turbulent vortex, which is continually driven by the bypassing flow. This vortex constantly dissipates energy. The frequency of the vortex $f_{\mathrm{V}}$ is an indicator for the energy dissipation (Leonhard et al., 2004):

$$
F_{V}=\frac{W}{\pi \cdot D}
$$

The static pressure drop in the centre of the turbulence aids the gas cavitation mechanisms. The air that is released by the oil during this mechanism is dragged downstream towards the rotating group, which leads to worsening of the filling of the displacement chambers and therefore leads to efficiency losses, (Bügener, 2014).

The validation of the CFD simulation is performed with means of differential pressure measurements across the suction duct. Figure 7 depicts the test rig setup as well as the comparison between simulation and experiment.

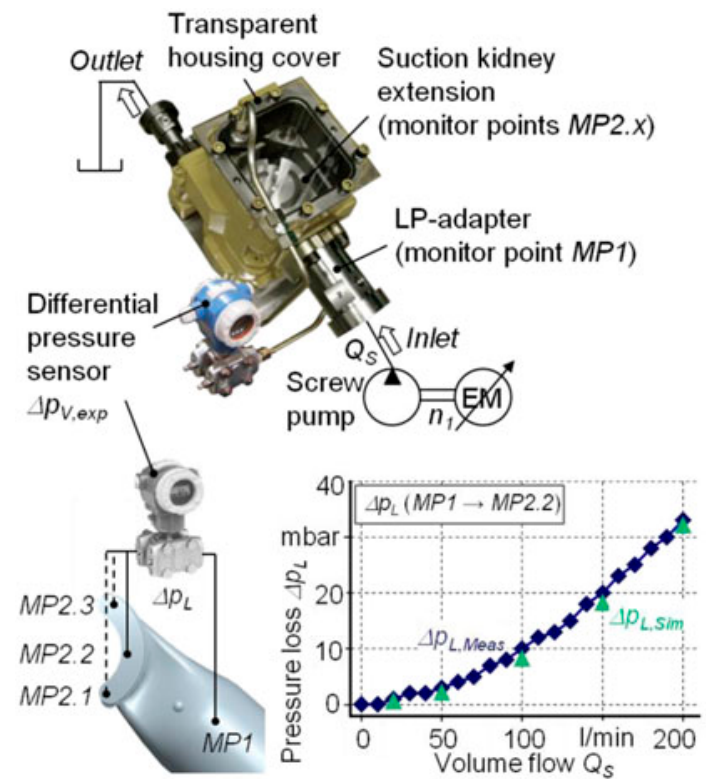

Figure 7. Comparison of measurement and CFD.

The measurement shows a high degree of compliance with the numerical results. The quadratic relationship for $\Delta p=\mathrm{f}(Q)$ can be recognized, which is typical for lossy laminar-turbluent/turbulent flow:

$$
\Delta p_{L}=\zeta \cdot \frac{\rho}{2} \cdot W^{2}
$$

Important aspects are also the flow conditions that not only occur in the suction duct, but more importantly also in terms of the arrangement regarding the rotating group. This needs to be studied in great detail.

\subsection{Interaction between Suction Flow and Rotating Group}

There is a strong discrepancy between the approaching flow $w_{S}$ and the circumferential flow component of the cylinder block $v_{C B}$, see Fig. 8 .

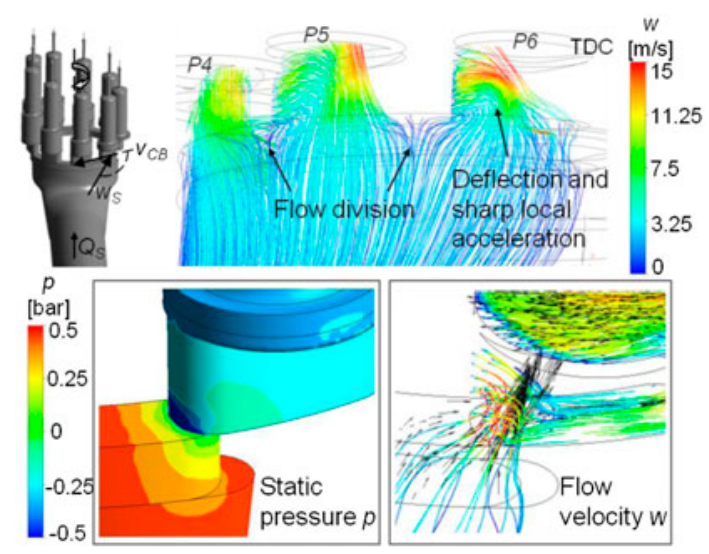

Figure 8. Deflection and acceleration losses due to the direction of the incident flow. 
The result is that the fluid experiences a high local acceleration as soon as it enters the displacement chamber, which leads to flow separation at the cylinder kidneys and causes high losses.

The suction flow is affected by a characteristic flow pulsation, which is due to the kinematics of the pump, the valve plate design and the mechanical properties of the fluid. A major cause for this pulsation is the decompression at the TDC as well as the lack of supply flow of the pistons at the beginning of the suction kidney.

The reversing process that occurs during the transition between high and low pressure majorly influences the suction process and the resulting pressure pulsation, see Fig. 9 and Fig. 10. The decompression flow from the piston back into the suction port, causes a shockwave, which travels upstream and can be seen in the pressure spike of the suction pressure.

Next to the pressure pulsation, also the filling process of the piston is being influenced in a negative fashion by this decompression flow. Figure 9 visualized the decompression stream of piston P6. It can be seen that this high intensity stream is transverse to the incident flow of piston P5, and therefore prohibits a proper filling of the displacement chamber. In practical this filling process is further hindered by the gas cavitation that occurs at the decompression process, which produces gas bubbles that are sucked into the displacement chamber, decreasing the volumetric efficiency (Wustmann, 2010, and Kunze, 1995). In the absence of a cavitation model, potential cavitation regions are identified by low-pressure areas in the CFD simulation. The lower the static pressure the higher the risk of cavitation.

Endurance tests under different operating conditions with runtimes of about 100 hours were performed to examine damages of the affected pump parts afterwards, e.g. the suction kidney as shown in Fig. 9 (Bügener, 2014).
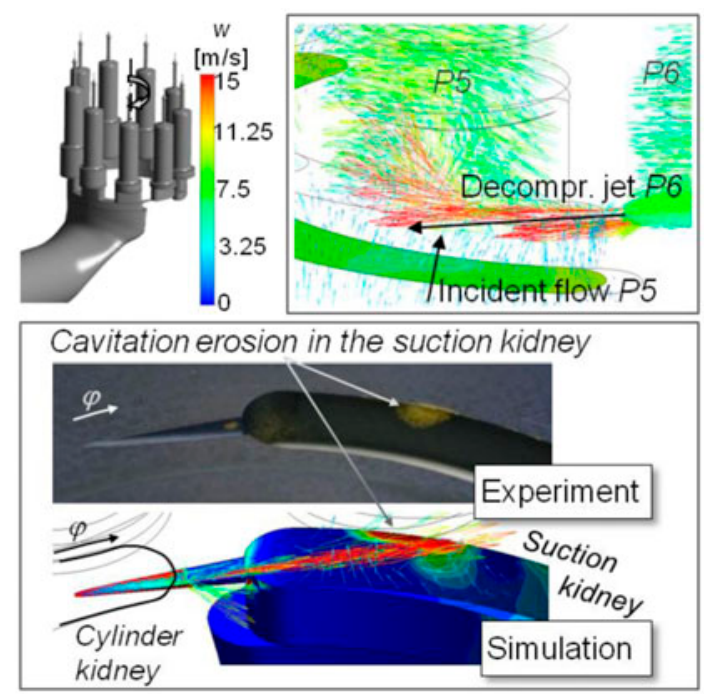

Figure 9. Reversing process in TDC.
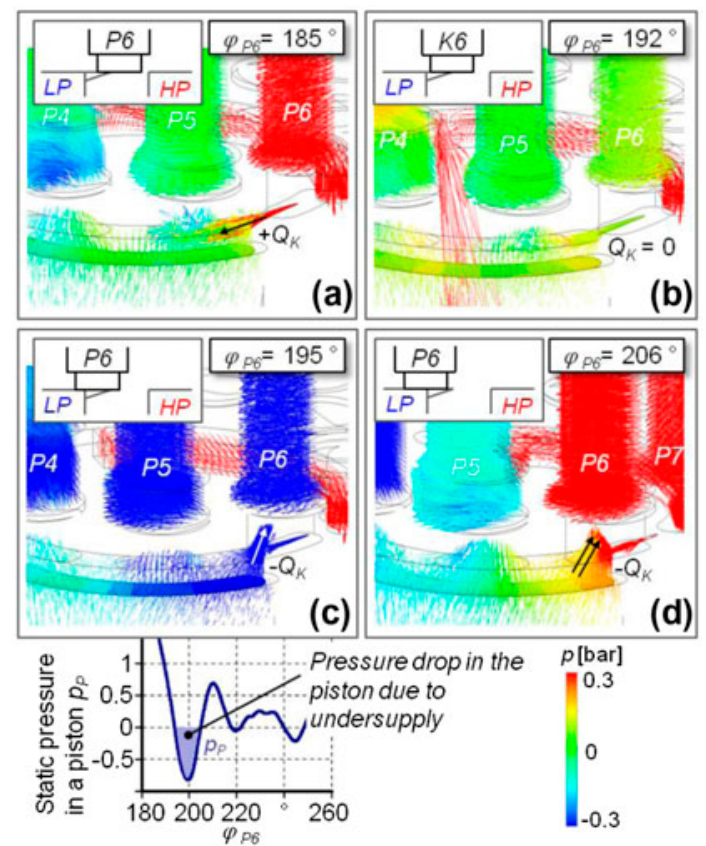

Figure 10. Undersupply conditions of the pistons.

Figure 9 shows that jet cavitation occurs due to the decompression stream and compares simulation with experiment. When the decompression stream hits the kidney wall a stagnation pressure region is formed, in which the created bubbles implode close to the wall causing erosion (Bügener, 2014).

Besides the decompression another effect has a major impact on the inlet flow pulsation, which is illustrated in more detail in Fig. 10. In the beginning of the reversing process, while the piston is discharging its pressure, a decompression flow is flowing from the piston chamber to the suction kidney (Fig. 10 a)). Once the pressure has been compensated the volumetric flow stops (Fig. 10 b)).

At this point in time the kinematic suction stroke has already begun. The piston velocity increases drastically whereas the cross sectional area between piston and kidney still remains rather small. Therefore the piston suction occurs through a small hydraulic diameter, which leads to an under-supply condition and pressure drop off in the piston displacement chamber (Fig. 10 c)).

With the advancing rotational angle of the cylinder block, the cross sectional area increases and a sudden pressure compensation occurs through fluid flow into the displacement chamber (Fig. $10 \mathrm{~d}$ )). This leads to a pressure drop in the suction duct and to the characteristic minima of the suction pressure pulsation, see Fig. 11. These minima are to be observed especially critical, since the pressure can drop into dangerous levels and gas cavitation can occur continually due to the periodical nature of the pressure drop of the suction pressure.

These highly dynamic transitional processes result in a characteristic suction pressure pulsation. Figure 11 shows the simulated pressure pulsation at the inlet of the pump and right underneath the suction kidney. 


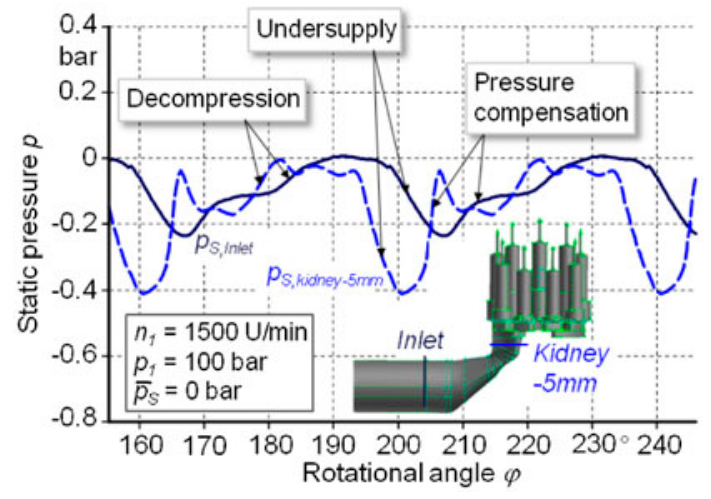

Figure 11. Suction pressure pulsation.

The numerical flow calculations allow for a better understanding of the specific events that are occurring during the suction stroke. This knowledge can be used to explain characteristic trends, show sources of losses and helps to derive approaches for the improvement of the suction performance.

The trend shown in Fig. 11 is to be taken merely qualitatively, since the content of free air in the suction line as well as the elasticity of the adjacent structure of suction line play a significant role in the flow ripple characteristic, but were neglected or strongly simplified in this case. In the following section of this paper the expansion of the suction line model is discussed in more detail, where the main focus will lie on the fluid-structure interaction and the implementation of a gas cavitation model.

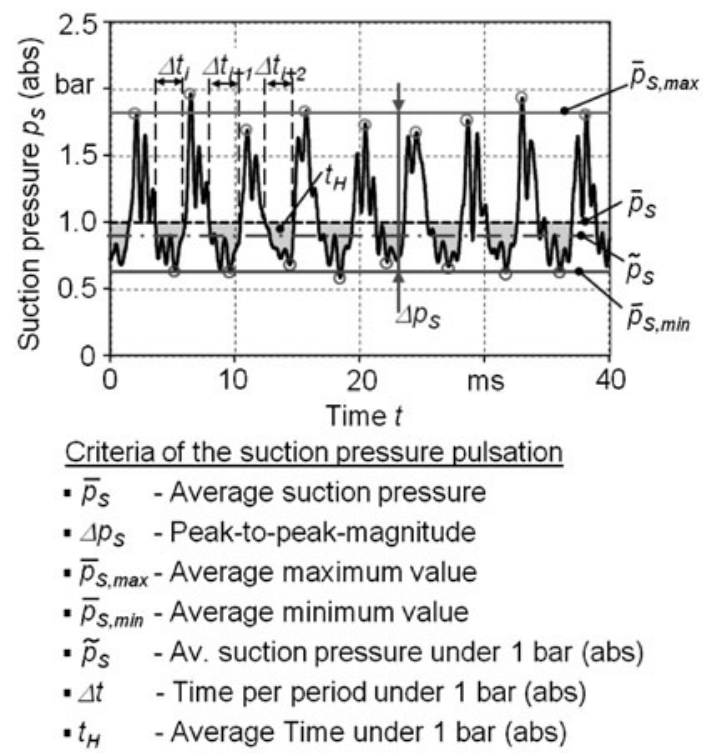

Figure 12. Characterisation of the suction pressure pulsation.

\section{Analysis Of The Suction Line}

Preliminary investigations (Bügener, 2014) defined several characteristic suction pressure levels (Fig. 12) to show the correlation between suction pressure pulsation and cavitation erosion of components of axial piston pumps. With endurance tests damages were detected at different operation points. Even cavitation erosion emerged, although the speed limits given by the manufacturer were complied and the suction conditions were admissible (average suction pressure $\bar{p}_{S}=1$ bar).

A correlation between the average minimum value of pulsation of the measured suction pressure signals $\bar{p}_{S \text { min }}$ and the damage was found as a result of the analyses. There is a threshold for $\bar{p}_{S \text { min }}$ that shows an inadmissible damage with lower deviation. Higher values for both average suction pressure and average minimum value of the pulsation allow for advantageous operation conditions. However, this threshold is not generally valid, but depends on the particular operating speed.

The Helmholtz resonator, described in the following section, aims at the reduction of the peak-to-peak amplitude $\Delta p_{S}$ and especially at an increase of the average minimum value $\bar{p}_{S \min }$.

For a better understanding of these complex circumstances CFD simulation were used in the recent years. Wustmann (2010) has shown not only good matches between CFD results and measurements for the reversing processes and high pressure pulsation of an axial piston pump, but also deficits in calculating the pressure pulsation in the suction line. In order to achieve better numerical accuracy the fluid-structure-interaction between the suction flow and the elastic suction line has to be considered. In addition, a more suitable cavitation model is required in order to calculate the gas cavitation processes more accurately. Gas cavitation primarily occurs in the suction line at low pressure levels, whereas vapour cavitation only occurs in the reversing groove. This is because the local static pressure falls below the vapour pressure of mineral oil $p_{\mathrm{v}}=50 \mathrm{mPa}$ (Findeisen, 2006) due to high flow velocities in the decompression jet stream. These two approaches are described in this section.

Figure 13 illustrates the influence of the line stiffness on the pressure pulsation in the suction line (Klecker, 2013). An almost rigid steel pipe and a very flexible

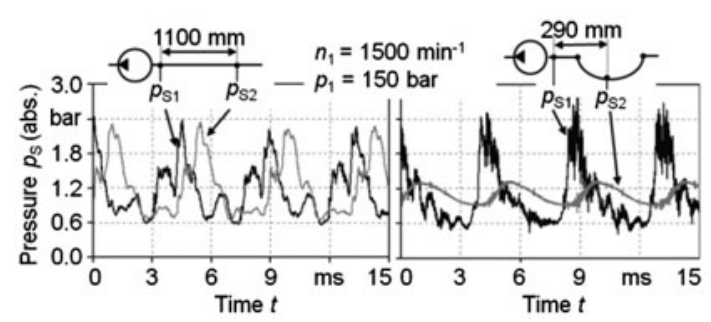

Figure 13. Pressure pulsation for a steel pipe (left) and a hose line (right). 
hose line were compared. As expected, there is a large difference in pressure damping between the steel pipe and the hose line. In contrast to the steel pipe, in which the pressure pulsation is nearly unchanged, the amplitude of the pressure pulsation in the hose line is significantly reduced.

Also, the more flexible hose material causes a reduction of the speed of sound $a$, which can be determined by the shorter distance the pressure wave propagates in the same time frame, Fig. 13. The speed of sound is the propagation velocity of pressure disturbances caused due to small density changes in compressible fluids and is defined as

$$
a=\sqrt{\frac{\partial p}{\partial \rho}}=\sqrt{\frac{K}{\rho}} .
$$

where $K$ is the bulk modulus of the elastic medium and $\rho$ its density. The water hammer equation by Joukowski (1898)

$$
\Delta p=\rho a \Delta W,
$$

describes the relation between the pressure amplitude $\Delta p$ caused by flow acceleration $\Delta w$ and the speed of sound $a$. The lower the speed of sound the smaller the pressure amplitude.

A test rig with a feedback control to adjust the average pressure level at the inlet port of the pump was used to show the impact of the free air volume fraction on the suction flow. A rigid steel pipe was chosen to minimize the material influence. Assuming the saturation pressure of the fluid is $p_{\text {sat }}=1$ bar two different average pressure levels at the pump inlet were set $\left(p_{\mathrm{S}, \text { high }}>p_{\mathrm{sat}}>p_{\mathrm{S} \text {, low }}\right)$ expecting a significant higher air volume fraction for the

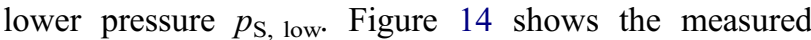
pressure signals for the two different pressure levels. At lower pressure and therefore larger free air volume fraction the damping is increasing. Even the pressure signal recorded close to the pump inlet shows a smaller pressure amplitude.

The speed of sound is an indicator for the intensity of the fluid-structure-interaction between the two-phase flow and the suction line. An analytical approach to calculate the speed of sound assuming a thin-wall pipe ( $\mathrm{s} / \mathrm{D} \leq 0,1)$ is described by Kottmann (1992):

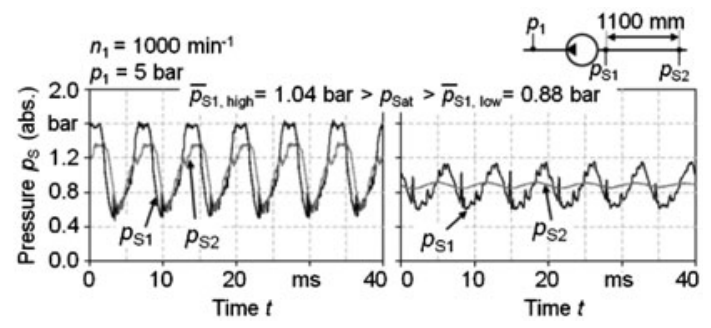

Figure 14. Pressure pulsation of the suction flow in a steel pipe for two different inlet pressure levels.

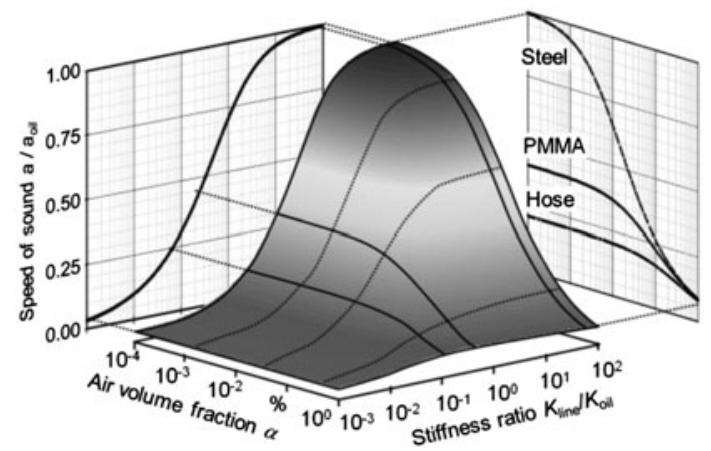

Figure 15. Coupled influence of line stiffness and air volume fraction on the speed of sound.

$$
a=\sqrt{\frac{K_{\text {mix }}}{\rho_{\text {mix }}\left(1+\frac{\left.\mathrm{D}_{\mathrm{s}}^{\left(1-\mathrm{v}^{2}\right) \mathrm{K}_{\text {mix }}}\right)}{\mathrm{E}}\right)}},
$$

with the Poisson ratio $v$, the inner diameter of the pipe $D$, the wall thickness $s$, Young's Modulus $E$ of the pipe material and the bulk modulus of the air-oil dispersion $K_{\text {mix }}$ and its density $\rho_{\text {mix }}$. Figure 15 visualizes Eq. (5) in a diagram.

\subsection{Fluid-Structure-Interaction (FSI)}

For the numerical investigation a method with a twoway FSI approach was developed using the commercial software ANSYS ${ }^{\circledR}$ Workbench. The suction line model was considered as a pipe segment with a length of $L=1 \mathrm{~m}$ and an inner diameter of $D=50 \mathrm{~mm}$, Fig. 16 . The suction line is elastically supported at both ends in radial and axial direction.

First, the line material behaviour is assumed to be linear elastic. In a further step viscoelastic material behaviour is added to the FSI-model. The mesh interface between the solid domain and the fluid domain is an 1:1 - grid interface with congruent nodes. The coupling algorithm used by ANSYS ${ }^{\circledR}$ Workbench is shown in Fig. 17. In order to obtain a strong coupling the minimum number of coupling loops is set to 3 and the maximum value is set to 20 and the criterion for the average residuals set to $10^{-5}$.

The mesh consists of hexahedral cells with a cell length of $\Delta x=5 \mathrm{~mm}$. The time step size is set to

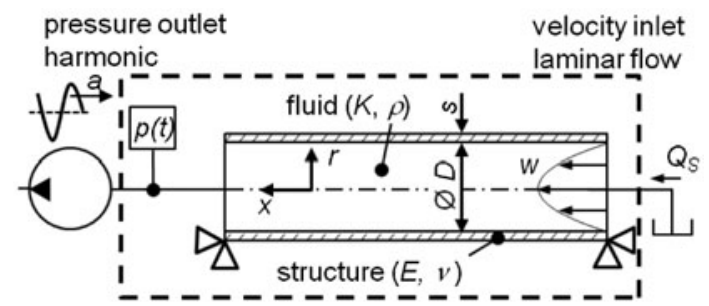

Figure 16. FSI-Model used for numerical calculations. 


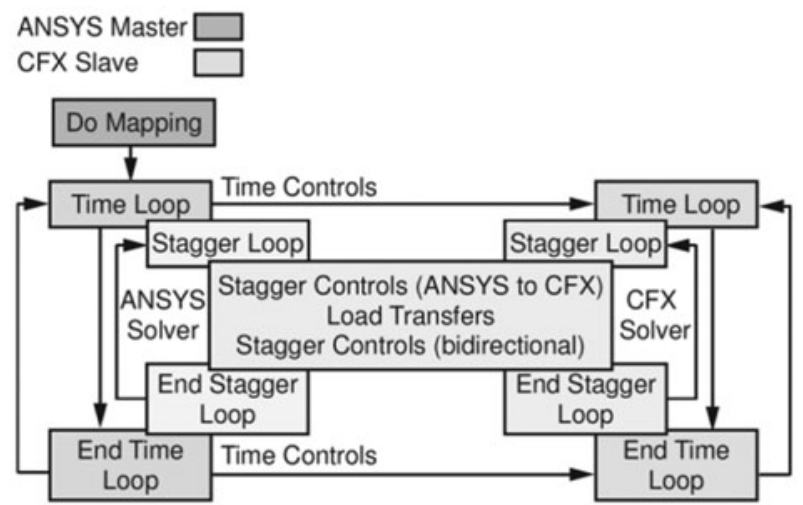

Figure 17. Flow chart of the ANSYS ${ }^{\circledR}$ FSI algorithm.

$\Delta t=\left(10^{-5} \ldots 10^{-6}\right) \mathrm{s}$ to meet the requirements given by the acoustic courant number CFL condition:

$$
C F L=\frac{a \Delta t}{\Delta X} \approx 1 \ldots 100 .
$$

Mineral oil ISO VG 46 is used and is considered as a compressible fluid with a pressure dependent density:

$$
\rho_{\text {oil }}=\frac{\rho_{\text {oil }, 0}}{1-\frac{p-p_{0}}{K_{\text {oil }}}}
$$

with the bulk modulus of the oil $K_{\text {oil }}$, and a reference density $\rho_{\text {oil }, 0}=870 \mathrm{~kg} / \mathrm{m}^{3}$, which corresponds to the reference pressure $p_{0}=1$ bar at temperature $\left(0=40{ }^{\circ} \mathrm{C}\right.$. The gas phase only consists of air with ideal gas properties. The air volume fraction is set to $\alpha=1.5 \times 10^{-3} \%$ at the corresponding pressure $p_{0}=1$ bar. In this section (4.1) no mass phase transfer is considered.

The suction flow with an average flow velocity $w=1 \mathrm{~m} / \mathrm{s}$ is laminar (Reynolds number $R e=1100<$ $\left.R e_{\text {crit }}=2300\right)$. For the use of a pipe segment a parabolic velocity profile at the inlet is specified for a fully

Table 1. Parameters of the FSI model.

\begin{tabular}{llll}
\hline Geometry & \multicolumn{3}{l}{} \\
\hline inner diameter & $D$ & $\mathrm{~mm}$ & 50 \\
pipe length & $L$ & $\mathrm{~mm}$ & 1,000 \\
wall thickness & $s$ & $\mathrm{~mm}$ & 5 \\
CSM (Computational Structural Mechanics) & \\
Young's modulus & $E_{\text {steel }}$ & $\mathrm{MPa}$ & 200,000 \\
& $E_{\mathrm{PMMA}}$ & $\mathrm{MPa}$ & 3,000 \\
& $E_{\text {hose }}$ & $\mathrm{MPa}$ & $10-300$ \\
Poisson ratio & $v_{\text {steel }}$ & - & 0.3 \\
& $v_{\mathrm{PMMA}}$ & - & 0.4 \\
& $v_{\text {hose }}$ & - & 0.4 \\
CFD & \multicolumn{3}{l}{} \\
bulk modulus & $K_{\text {oil }}$ & $\mathrm{bar}$ & 15,000 \\
oil density & $\rho_{\text {oil }}$ & $\mathrm{kg} / \mathrm{m}^{3}$ & 870 \\
viscosity & $\eta_{\text {oil }}$ & $\mathrm{Pa} \mathrm{s}$ & 0.04 \\
pressure & $p_{0}$ & $\mathrm{bar}$ & 1.0 \\
flow velocity & $w$ & $\mathrm{~m} / \mathrm{s}$ & 1.0 \\
temperature & $\vartheta$ & ${ }^{\circ} \mathrm{C}$ & 40 \\
initial free air volume fraction & $\alpha_{0}$ & $\%$ & 0.0015 \\
\hline
\end{tabular}

developed laminar flow in order to avoid inflow pressure losses. The pressure ripple caused by the pump is idealized and specified as a harmonic pressure signal at the outlet. The frequency is given by the pump speed. The amplitude of the pressure pulsation is derived from measurements. The most important parameters are listed in Table 1 below.

Different line materials were compared by varying the Young's Modulus E, e. g. steel, acrylic glass (PMMA) and rubber (NBR) in order to investigate the applicability of the FSI model. In comparison with the analytical approach given by Eq. (5) the calculated speed of sound for different line materials matches the theoretical ones very well.

For further validation of the FSI approach a test rig was built to determine the speed of sound of static mineral oil HLP 46 in a closed acrylic glass pipe, Fig. 18.

Therefore, the numerical model had to be customized considering the test rig conditions. The new settings are listed below:

initial flow is set to zero

fixed wall instead of a velocity inlet

moving wall instead of an harmonic pressure outlet

The movement of the shaker driven hydraulic cylinder causes a single pressure impulse, which propagates through the pipe with the speed of sound. Four high dynamic pressure sensors along the pipe were measuring the pressure signal.

With the time duration $\Delta t$ and the distance $\Delta s$ between the sensors the speed of sound can be calculated by $a=\Delta s / \Delta t$. The amplitude of this generated pressure impulse is related to the piston velocity (Eq. 4) and was adjustable by setting the voltage input signal of the shaker drive using a function generator.

The piston stroke of the shaker was recorded with a laser distance sensor in order to specify the time

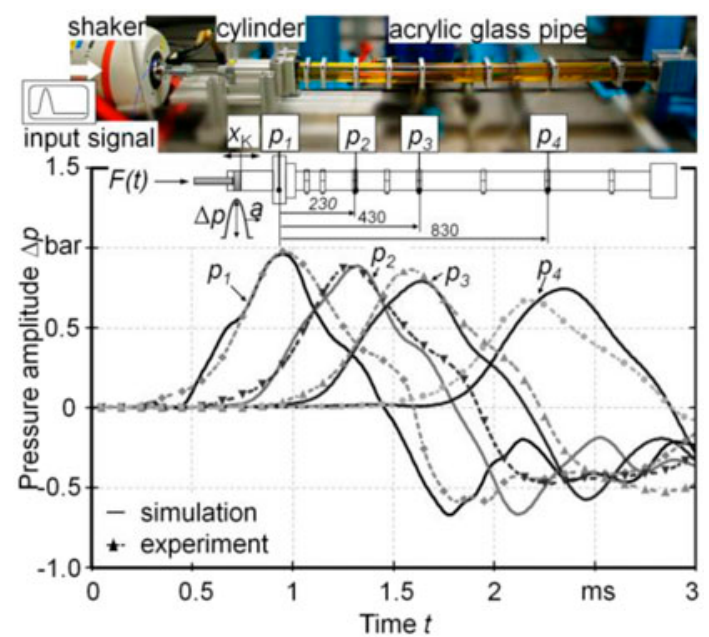

Figure 18. Validation of the FSI-Model. 
dependent displacement of the moving wall in the CFD model. As it can be seen in Fig. 18 the CFD results matches the measurements at the first part of propagation (pressure maxima). At the low pressure peaks the differences are getting bigger.

In the next step, a viscoelastic material model based on the Prony method is added in order to calculate the suction flow in hose lines. The Prony series data of a reference elastomer NBR found in Bormann (2005) is representative for most hydraulic hoses. The layered design (inner and outer layer made of NBR, textile mesh in the middle) of hydraulic hoses is set up in the numerical model. Because of the unknown Young's modulus of the mesh textile the mixed hose line stiffness was experimentally determined using the previous described test rig. A validation of the viscoelastic material model with the layered hose design is carried out in section 4.3.

\subsection{Gas Cavitation}

The initiation of gas cavitation in the suction line is the main cause for the speed limit of open circuit piston pumps. A suitable approach to consider gas cavitation mechanisms is the Full Cavitation Model (FCM) by Lifante and Frank (2008) and is an extension of the FCM by Singhal et al. (2002) and Yang et al. (2005). In contrast to the vapour cavitation model based on the Rayleigh-Plesset equation the mass transfer rate $R$ for gas cavitation is related to the equilibrium pressure, which follows Henry-Dalton's law. The equations to calculate the mass transfer rate per unit volume $R$ for desorption and absorption are defined as:

$$
\begin{gathered}
R_{\mathrm{abs}}=C_{\mathrm{abs}} \rho_{\text {Air }}\left(p-p_{\text {equil }}\right)\left(f_{D A, \mathrm{lim}}-f_{\mathrm{DA}}\right) f_{\text {Air }} \\
R_{\mathrm{des}}=C_{\mathrm{des}} \rho_{\text {Air }}\left(p_{\text {equil }}-p\right)\left(1-f_{\text {air }}\right) f_{\mathrm{DA}},
\end{gathered}
$$

where $f_{\mathrm{Air}}$ and $f_{\mathrm{DA}}$ is the mass fraction of free air respective the mass fraction of dissolved air and the equilibrium pressure $p_{\text {equil }}$, depending on the molar fraction $X_{\mathrm{DA}}$ and the Henry constant $H_{\mathrm{DA}}$ :

$$
p_{\text {equil }}=H_{\mathrm{DA}} X_{\mathrm{DA}} \text {. }
$$

The FCM was validated for water flows. Thus, the model has to be customized for mineral oil HLP 46. The problem is, that material properties of mineral oil with regard to gas cavitation are mainly unknown. Hence, another test rig was built in order to determine specific material properties, e. g. air solubility or time constant of air release. With the test rig, an over- or undersaturation of an oil probe can be generated.

In this case the time dependent mechanisms of absorption and desorption can be analysed in detail. The FCM was customized using the new determined parameters for HLP 46, which are the basis for further numerical works. Figure 19 shows the CFD results applying the adapted FCM for a closed oil probe in a cylinder. The periodic supersaturation $\left(p<p_{\text {sat }}\right)$ caused by the

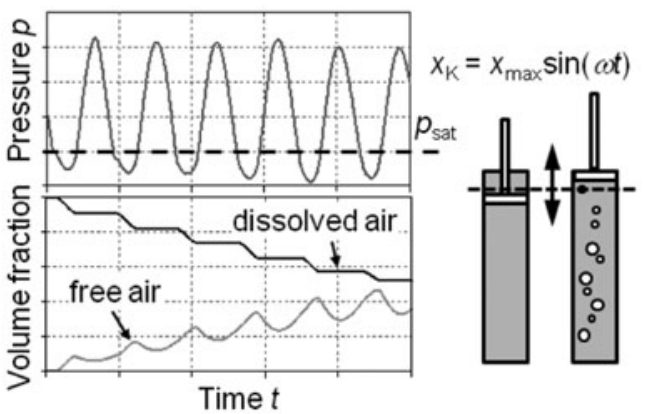

Figure 19. Release of dissolved air due to periodic supersaturation in a closed volume.

harmonic piston stroke leads to a steady increase of the free air volume fraction.

\subsection{Comparison between Simulation and Experiment}

Measurements for different pump speeds were carried out to investigate the frequency dependent damping behaviour of viscoelastic hose lines. The pressure signals were recorded up- and downstream of the hose line. The results are shown in Fig. 20.

The upstream pressure pulsation $p_{\mathrm{S} 2}$ decreases at high pump speed. This is a result of the viscous part of the hose material. The changes in the pressure signal near the pump $p_{\mathrm{S} 1}$ are more important for the pump performance and will be discussed below.

At a constant pump speed the upstream pressure pulsation damping is not only caused by the viscous damping along the hose line but also by partial reflections, which occur at the hose fitting location, Fig. 21. The reason for these partial reflections is the sudden change of the line impedance due to the significant difference between the Young's modulus of the fitting material (steel) and the hose material (NBR).

The amplitude of the reflected pressure wave can be calculated with the reflection factor (Kottmann, 1992):

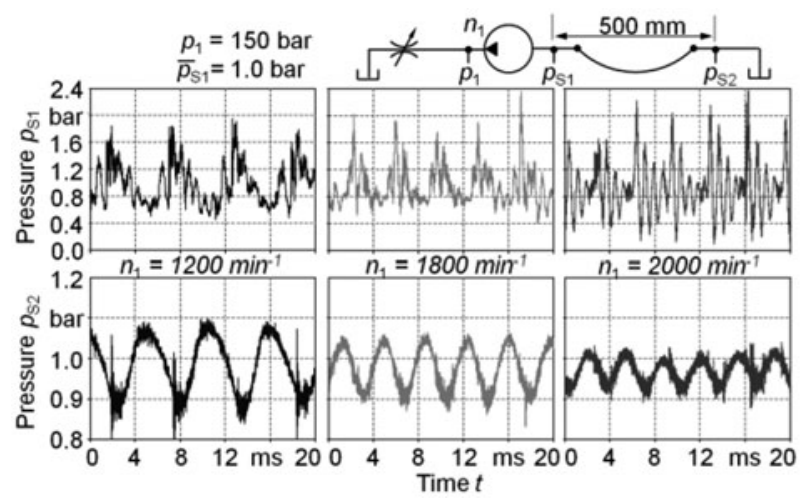

Figure 20. Frequeny dependent damping of the pressure pulsation in hose lines. 


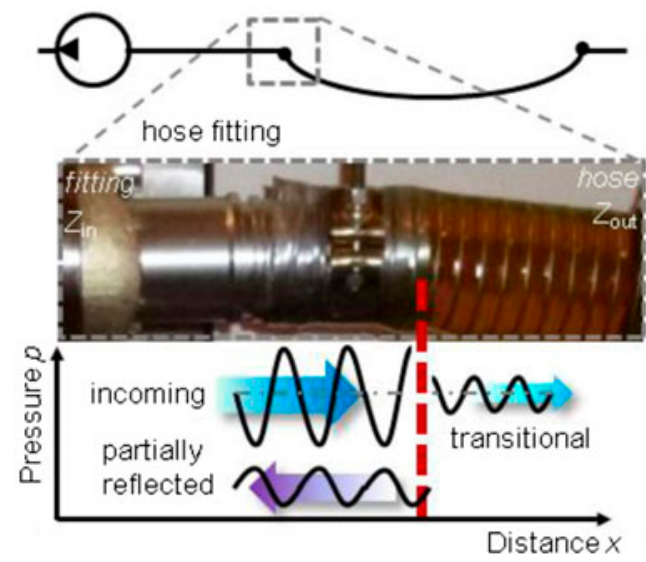

Figure 21. Partial reflections due to sudden impedance change at hose fittings.

$$
R=\frac{\hat{\rho}_{r}}{\hat{\rho}_{\text {in }}}=\frac{1-Z_{\text {in }} / Z_{\text {out }}}{1+Z_{\text {in }} / Z_{\text {out }}}=\frac{1-a_{\text {in }} / a_{\text {out }}}{1+a_{\text {in }} / a_{\text {out }}}
$$

where $Z$ is the impedance of the line segment depending on the line material and $\hat{p}$ is the amplitude of the incoming and reflected pressure waves. The higher the differences of the impedances the higher the amplitude of the reflected pressure wave and the smaller the amplitude of the transitional pressure wave. Analytical calculations show that the amplitude of the transitional pressure wave is in the range of $10 \%$ from the incoming wave, see Table 2 below. Because of energy conversation the amplitude of the transitional wave is $d=1+r$.

As a result, the measured pressure pulsation between the pump and the hose line $p_{\mathrm{S} 1}$ is a superposition of the pressure wave caused by the pump and the opposed wave reflected at the hose fitting. As a consequence, in the important region close to the pump inlet the pressure minima fall with increasing speed, even though the pressure pulsation in the hose line is significantly reduced and smoothened.

The numerical investigations were carried out using the FSI-approach and the adapted FCM including a pressure boundary condition based on measured pressure signals. In Fig. 22 the simulation results are compared to the corresponding experimental ones. As it can be seen the calculated pressure signal in the hose line is very close to the measured one.

Table 2. Reflection factor depends on the line material and compressibility of the oil-air mixture.

\begin{tabular}{llccc}
\hline & \multicolumn{3}{c}{$\begin{array}{c}\text { Young's modulus } E \text { of } \\
\text { the line in } \mathrm{MPa}\end{array}$} \\
\cline { 2 - 5 } Reflection factor $\boldsymbol{r}$ & & 10 & 100 & 1000 \\
\hline bulk modulus $K_{\text {mix }}$ in bar & 16,000 & -0.95 & -0.86 & -0.62 \\
& 10,000 & -0.94 & -0.82 & -0.55 \\
& 1,000 & -0.83 & -0.55 & -0.18 \\
\hline
\end{tabular}

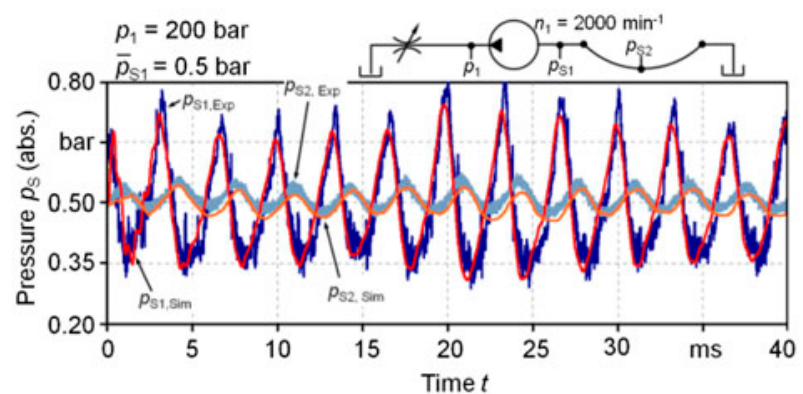

Figure 22. Comparison between simulation and experiment for the pressure pulsation.

To conclude, the fluid-structure interaction and the gas cavitation have to be considered for the CFD simulation to obtain high accuracy. The two main appropriate methods (FSI and customized FCM) are described in this section. Further investigations will be performed using the rotating group of the axial piston pump instead of a harmonic pressure signal at the outlet boundary of the suction line. Moreover, the fluid properties of mineral oil concerning gas cavitation, in particular, the shear stress dependent time constants, will be analysed in future measurements in order to extend the FCM.

\section{Improvement Of The Suction Performance}

\subsection{Meander Shape Suction Duct Design}

The minimal flow resistances in meandering rivers result from a continuous adjustment process to the most energy-efficient flow path. Meander shapes do not form at random, but they follow physical laws. Irregularities in the riverbed affect the straight course of the river. Besides these external influences furthermore internal processes (flow separation, turbulences) occur and support the meander formation. By superposition of the main flow with a secondary transverse flow, which is friction-caused, a strengthened formation of the convex and concave bank occurs, see Fig. 23.
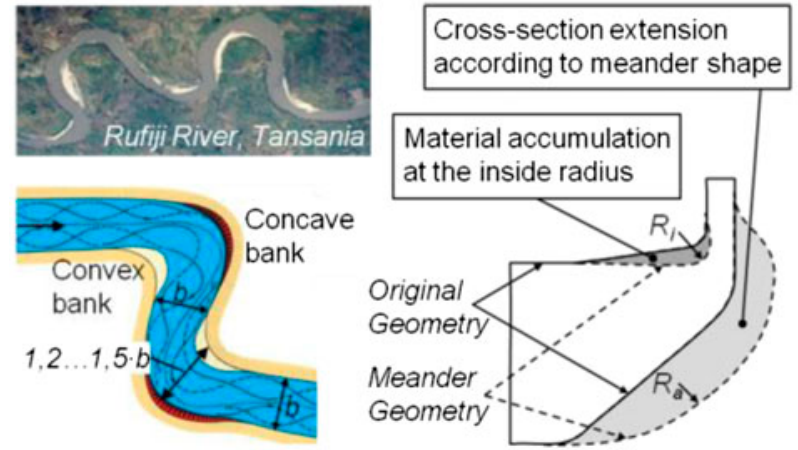

Figure 23. Geometry of meandering rivers and transfer to the suction duct design. 
The secondary flow is subject to inertia. This leads to the effect that the highest circulation occurs short behind the place with the strongest curvature. This is valid also for the intensity of the erosion and leads to the typical topology of strongly meandering rivers. In the area of the curvature a widening of the river bed is observable by the factor of $1.2 \ldots 1.5$ of the width $b$ of straight river sections. By viewing the topology of meander bends it is striking that the flow geometry has no even radius. An initially slight bending proceeds to an increasingly stronger turn and swings back at the end of the curvature, see Fig. 23.

The radius/diameter-ratio $(R / D)$ is a criterion for the development of a flow-optimized $90^{\circ}$-bend. Losses in $90^{\circ}$-bends of pipes can be reduces according to Idelchik (2006) by means of a defined extension of the cross-section in the vertex of the curvature. Similar extensions are observable in meander bends.

The deflection was modified following the shape of meander bends. At the internal radius, where the danger of flow separation is particularly high, a material accumulation comparable to the convex bank occurred. Thereby an increased internal radius $R_{i}$ arises. The shape of the external radius $R_{a}$ is characterised by a cross-section enlargement at the apex and by continuously declining radius of curvature in direction of the flow. Radius $R_{a}$ is initially slowly and then increasingly stronger declined in purpose of a setting premature velocity component in transverse direction in order to reduce the acceleration of the flow within the deflection and thus the related losses. The cross-section enlargement at the apex reduces the flow velocity in the area of the strongest deflection and consequently the viscous losses. Figure 23 shows the symmetrical cross sectional plane of the original suction duct design and of the meander geometry.

The design implementation of the suction duct variations takes place by means of gradually adjusted crosssectional areas which are arranged along a guideline. In Fig. 24 the original suction duct design and two meander geometries are illustrated.

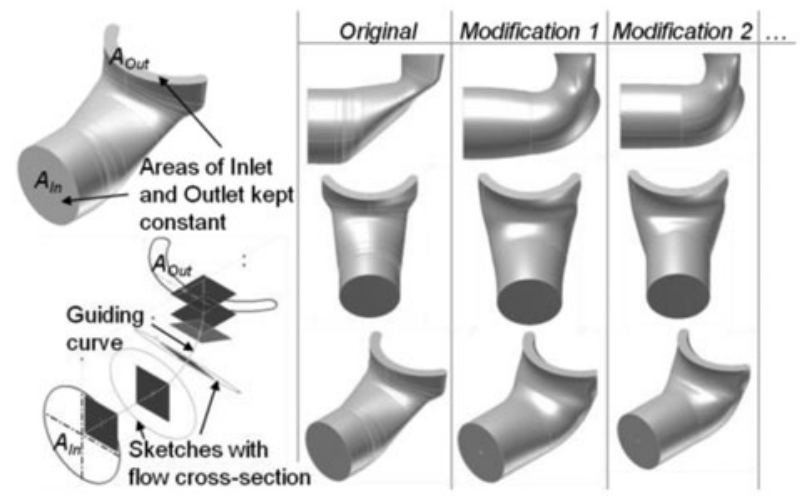

Figure 24. Modification of the suction duct.
For the development of the improved suction duct designs and their evaluation steady-state CFD simulations were used. The rotating group is not considered at this time.

The investigated operating point has a rotational speed of $n_{1}=1500 \mathrm{U} / \mathrm{min}$. Consequently a constant flow velocity of $w=0,9 \mathrm{~m} / \mathrm{s}$ is set as the boundary condition at the inlet of the $7 \mathrm{~m}$ long suction line. At the outlet of the flow region, the suction kidney, a pressure boundary condition of $p=1 \mathrm{bar}$ (abs) is used. The investigations are carried out with incompressible fluid $\left(\rho=860 \mathrm{~kg} / \mathrm{m}^{3}=\right.$ const. $)$, while applying the SST-turbulence-model.

The evaluation of the suction duct designs is based on the pressure drop between the pump inlet and the suction kidney. The total pressure $p_{\text {tot }}$, consisting of the static pressure $p_{\text {stat }}$ and the dynamic pressure $p_{\mathrm{dyn}}$ :

$$
P_{t o t}=p_{\text {stat }}+p_{d y n}
$$

is used for the evaluation of the total energy losses. The static pressure allows predictions with respect to the risk of cavitation. The calculated pressure losses are normalized to the static pressure loss of the original geometry as a reference value. The meander geometries show considerably reduced pressure losses, as it is illustrated in Fig. 25.

With nearly $60 \%$ reduced static pressure loss and $50 \%$ less total pressure loss $\Delta p_{L, \text { tot }}$ with regard to the original geometry, modification 1 shows the greatest improvement. As the main causes of the decreased pressure losses the reduced flow separation at the internal radius and the decreased flow velocity within the suction duct can be identified. Figure 26 shows the pressure distribution of the original and the meander geometry as well as the contour plot for the flow velocity in the symmetry layer of both suction ducts.

Following the most efficient option, modification 1, is investigated with the dynamic 9-piston-model of the axial piston pump considering the interaction with the rotating group and the oscillating flow. Figure 27 illustrates the comparison between the simulated pressure losses of the suction duct designs applied in the simulations.

The static pressure loss between suction port of the pump and suction kidney could be reduced by $55 \%$, by

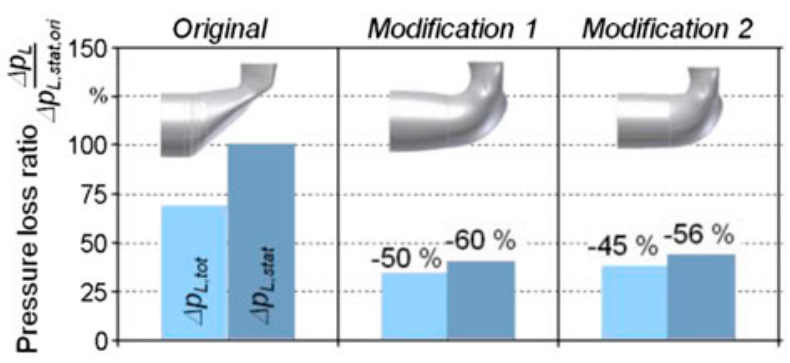

Figure 25. Pressure losses across different suction duct designs. 


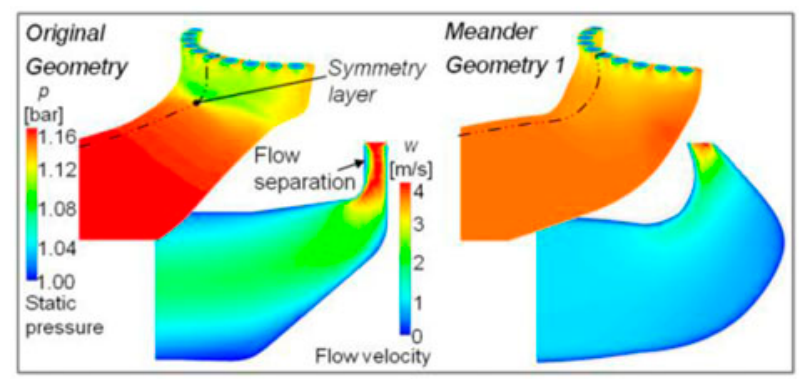

Figure 26. Comparison of original and meander geometry.

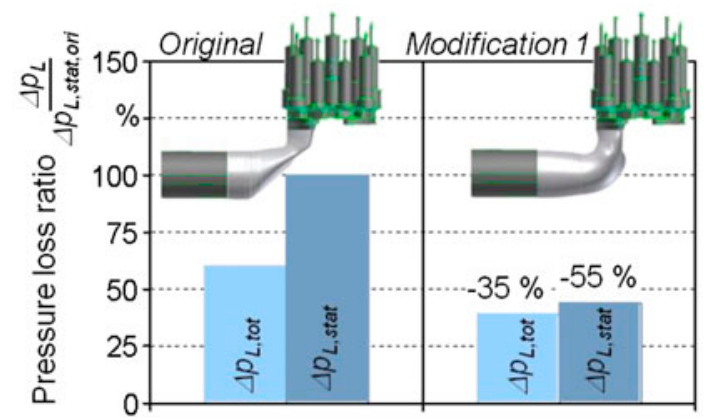

Figure 27. Pressure losses across the suction duct designs considering the rotating group.

applying modification 1 . The total pressure loss $\Delta p_{L, t o t}$ was reduced by $35 \%$. Thus the simulations with the 9 piston-model confirm the results of the steady-state calculations. In comparison with the steady-state model the reduction in pressure losses are smaller due to the flow ripple and the interaction with the rotating group.

\subsection{Reduction of the Suction Pressure Pulsation by Means of a Helmholtz Resonator}

Due to the elasticity $c_{H R}$ of the fluid volume in combination with the inert mass $m_{H R}$ of the fluid within the junction the Helmholtz resonator is an equivalent to a mechanical spring-mass-damper-system with a distinctive natural resonance $\omega_{0}$, see Fig. 28.

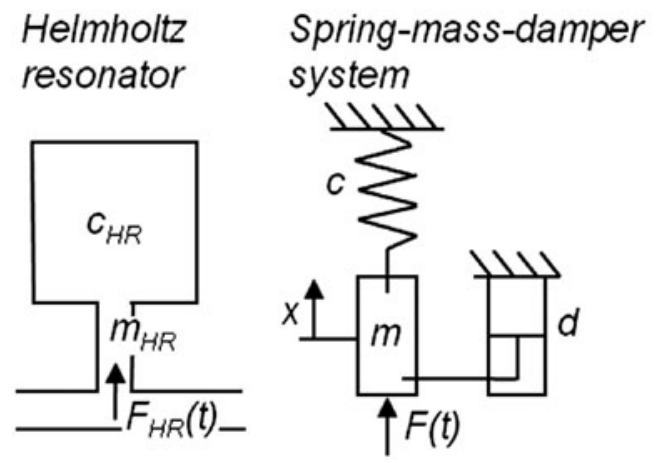

Figure 28. HR as equivalent to a mechanical spring-mass-damper system.
The resonance frequency $f_{R}$ of the HR can be calculated, depending on its geometric and fluid parameters, according to:

$$
f_{R}=\frac{1}{2 \pi} \cdot \sqrt{\frac{c_{H R}}{m_{H R}}}=\frac{a}{2 \pi} \cdot \sqrt{\frac{A_{H R}}{V_{H R} \cdot\left(L_{H R}+\frac{\pi}{4} \cdot D_{H R}\right)}}
$$

However, because of the neglect of friction it is not possible to draw conclusions of the amount of damping in the case of resonance.

The term $1 / 4 \pi D_{H R}$ is called port correction factor and has to be considered because not only the fluid volume within the junction oscillates, but also an extra volume, depending on the shape of the port, see Fig. 29. According to Kiesbauer (1991) the shape of the volume has no influence on the functionality as long as there is a proper relation between volume and orifice. The effective junction length $L_{H R}{ }^{*}$ is:

$$
L_{H R}^{*}=L_{H R}+\frac{\pi}{4} \cdot D_{H R}
$$

Reflection dampers as the HR use interferences of the acoustic wave with their reflection. Figure 29 illustrates the functional principle when applied to the suction line.

The pressure pulsation expands in wave form against the flow direction with the speed of sound $a$. By superposition of this primary wave and the second wave of equal frequency and preferably equal amplitude achieves the damping effect. The secondary wave results from particular reflections of the primary wave at sudden changes of the wave impedance $Z$ of the suction line, e. g. the junction of the resonator. The reflected wave has a phase shift of $180^{\circ}$ (Goenechea, 2007).

The damping ability of a Helmholtz resonator is mainly influenced by the complex impedances of the suction line and the resonator junction, which are opposed to the primary wave emitted by the pump. The ratio of the input impedances of the junction $Z_{H R}$ and of the suction line $Z_{L}$ defines the damping. For:

$$
\frac{Z_{H R}}{Z_{L}} \Longrightarrow 0
$$
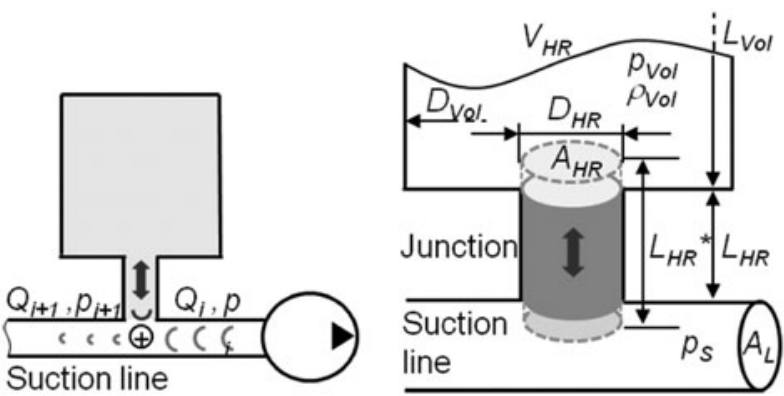

Figure 29. Functional principle and geometry parameters. 
the pulsation damping strives against its optimum. For the friction-free case the impedance $Z_{L}$ can be calculated in dependence on the fluid parameters and the cross section of the line according to:

$$
Z_{L}=\frac{\hat{p}}{\hat{Q}}=\frac{\sqrt{K^{\prime} \cdot p}}{A_{L}} .
$$

The impedance of the Helmholtz resonator can be written as:

$$
Z_{H R}=\frac{\hat{p}_{S}}{\hat{Q}_{H R}}=\frac{i \cdot \rho_{A B Z} \cdot L_{H R}}{\omega \cdot A_{H R}} \cdot\left[\omega^{2}-\frac{a^{2} \cdot A_{H R}}{V \cdot L_{H R}}\right]
$$

A comparison with equation (18) shows that in resonance the term in square brackets and thus the impedance become zero. The sound energy absorbed by the resonator becomes maximum. Exclusively the friction and the compressibility within the junction and the resonator volume prevent a total elimination of the pressure wave.

For the evaluation of dampers the insertion loss $D_{E}$, indicated in decibel, can be used. It defines the change of pulsation by applying the resonator referring to the state without resonator:

$$
D_{E}=10 \cdot \log \left(\frac{\Delta p_{o R}^{2}}{\Delta p_{m R}^{2}}\right)
$$

The challenge of the integration of the Helmholtz resonator into the pump results from the stringent restrictions regarding the installation space. Furthermore it is convenient to locate the resonator as close as possible to the main source of the pulsation. The effective, however narrow-band damping characteristics lead to the demand of an adaptive design of the Helmholtz resonator in order to adjust the resonant frequency of the damper that is necessary for different rotational speed levels of the pump. Manufacturing inaccuracies and friction lead to a shift of the effective resonant frequency and also support the demand for adaptability of the integrated HR.

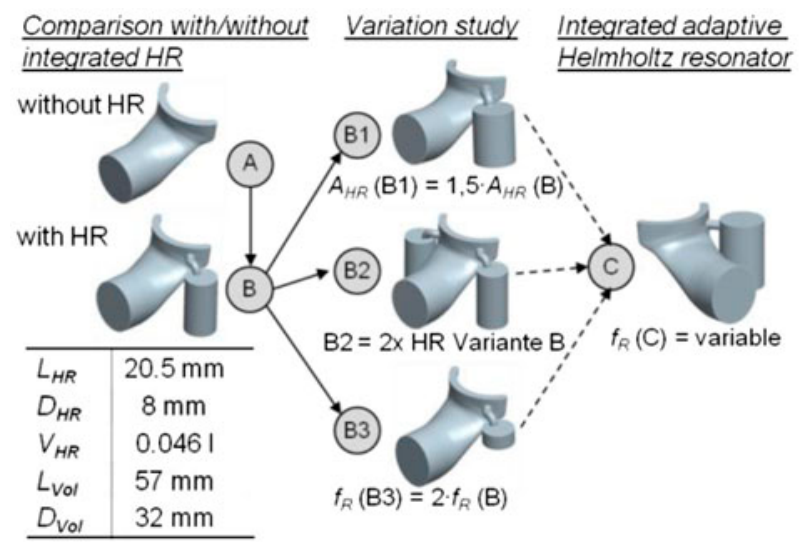

Figure 30. Investigated designs of integrated Helmholtz resonators.
The numerical investigations of the integrated resonator include a comparison of the pulsation with and without HR as well as a variation study. The focus is on three variations:

- HR with detuned resonant frequency

- Reduced junction impedance by means of increased junction diameter

- Use of a second HR at the end of the suction kidney

Figure 30 shows the investigated variations. To reduce the calculation time the rotational group is neglected for these simulations. In order to replicate the transient flow conditions along the suction kidney ten equidistant circular areas with different transient pressure profiles are used. These profiles result from a simulation with the rotational group.

Figure 31 shows the simulation results for the pulsation with and without HR in time and frequency domain. Compared to the initial situation without resonator (A, green curve) the suction pressure pulsation could be reduced by $D_{E}=9.2 \mathrm{~dB}$ by means of the integrated resonator (B, dark blue curve). The variations B1, B2 and B3 (light blue curves) are derived from variation B.

The reduction of the junction impedance in B1 leads to a slightly improved damping behaviour. The insertion loss is $D_{E}=9.5 \mathrm{~dB}$. Moreover the average minimum suction pressure, which goes along with continuous risk of gas cavitation due to the periodical pressure drops in cavitation critical pressure levels, could be raised to uncritical pressure levels above $p_{s}=0,8$ bar (abs).

In Variation B2 two identical HR (B) are used, at the beginning and the end of the suction kidney. This configuration shows an deterioration. The frequency spectrum
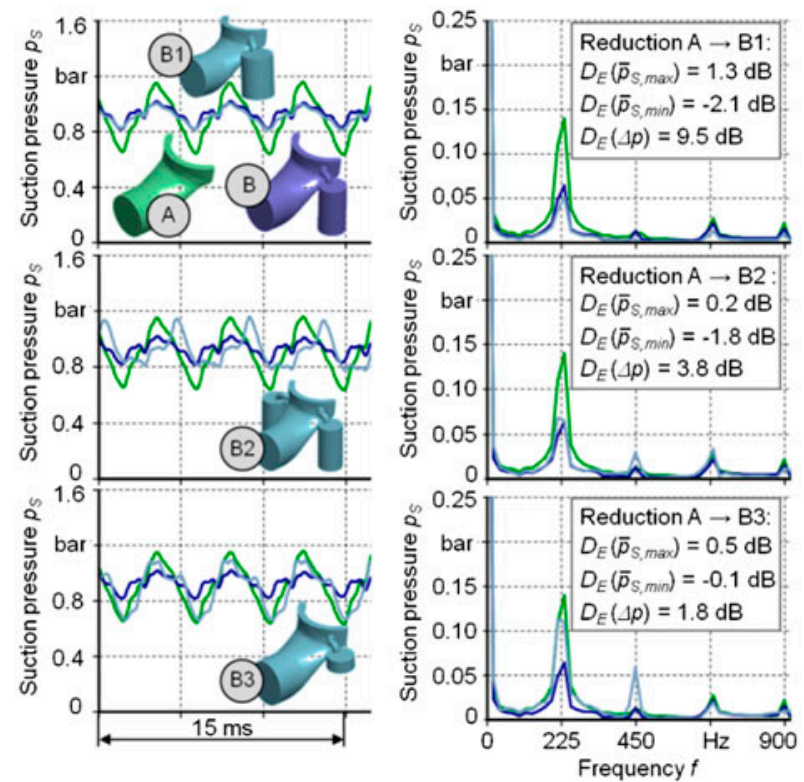

Figure 31. Comparison of investigated designs. 
illustrates that at the pump base frequency of $f_{0}=225 \mathrm{~Hz}$ the damping is comparable to variation B. However, the harmonic frequency components, especially the double base frequency of $450 \mathrm{~Hz}$, occur intensified. This can be traced back to the interaction of both resonators.

Variation B3 aims at the tuning of the resonator frequency to the double base frequency of the pump $f_{R}=2 \cdot f_{0}=450 \mathrm{~Hz}$. Therefore the resonator volume was reduced to a quarter of the initial value. The excitation frequency stays at $225 \mathrm{~Hz}$. The curves in Fig. 31 show that the base frequency keeps almost undamped. Furthermore there is an increased excitation of the suction pressure pulsation with a frequency of $f=450 \mathrm{~Hz}$, which correlates with the resonant frequency of the Helmholtz resonator.

\section{Summary And Outlook}

In this paper the suction performance of an axial piston pump, a key component in fluid power, was analysed. By means of fluid-structure-interaction and a customized cavitation model considering gas cavitation for mineral oil a high accuracy of the CFD calculations has been obtained. On the basis of steady-state and transient CFD simulations, where the main focus was on the analysis of the losses during the suction process, two original improvement measures are presented. The design of the suction duct following the shape of meandering rivers aim at a low-loss flow from the pump inlet to the suction kidney. With more than $50 \%$ reduced static pressure losses, a significantly improved situation for the inflow into the rotating group occurs. By means of the integration of a Helmholtz resonator near the main source of the suction pressure pulsation both the pulsation magnitude and the average minimum suction pressure could be improved. Furthermore, the design studies of the integrated HR have shown the high potential for an industrial application.

After the numerical investigations and the numerical developed improvement measures, the next step has to be the experimental verification of the effectiveness of the measures as well as the impact on the speed limit of the pump. Further experimental works should be considering the flow ripple as a specific indicator of the pump performance.

\section{Nomenclature}

$\begin{array}{lll}a & \text { Speed of sound } \quad[\mathrm{m} / \mathrm{s}] & \\ A_{\mathrm{HR}} & \text { Cross section of junction } \quad\left[\mathrm{m}^{2}\right] \\ A_{\mathrm{L}} & \text { Cross section of the line }\left[\mathrm{m}^{2}\right] & \\ c_{\mathrm{HR}} & \text { Stiffness of Helmholtz resonator } & {[\mathrm{N} / \mathrm{m}]} \\ C_{a b s} & \text { Absorption coefficient } & {[\mathrm{m} \mathrm{s} / \mathrm{kg}]} \\ C_{d e s} & \text { Desorption coefficient } & {[\mathrm{m} \mathrm{s} / \mathrm{kg}]} \\ C F L & \text { Courant number }[-] & \\ d & \text { Amplitude of transitional wave } & {[-]} \\ D & \text { Diameter }[\mathrm{m}]\end{array}$

\begin{tabular}{|c|c|}
\hline$D_{\mathrm{HR}}$ & Junction diameter $[\mathrm{m}]$ \\
\hline$E$ & Young's modulus $\left[\mathrm{N} / \mathrm{m}^{2}\right]$ \\
\hline$f$ & Mass fraction $[-]$ \\
\hline$f_{0}$ & Natural frequency $[\mathrm{Hz}]$ \\
\hline$f_{\mathrm{R}}$ & Resonance frequency $[\mathrm{Hz}]$ \\
\hline$f_{\mathrm{V}}$ & Frequency of vortex $[\mathrm{Hz}]$ \\
\hline$H_{\mathrm{DA}}$ & Henry constant [bar] \\
\hline$k$ & Turbulent kinetic energy $\left[\mathrm{m}^{2} / \mathrm{s}^{2}\right]$ \\
\hline$K$ & Bulk modulus $\left[\mathrm{N} / \mathrm{m}^{2}\right]$ \\
\hline$L$ & Length $[\mathrm{m}]$ \\
\hline$L_{\mathrm{HR}}$ & Junction length of $[\mathrm{m}]$ \\
\hline$m_{\mathrm{HR}}$ & $\begin{array}{l}\text { Mass of fluid volume in the Helmholtz } \\
\text { resonator }[\mathrm{kg}]\end{array}$ \\
\hline$n$ & Pump speed $\left[\mathrm{min}^{-1}\right]$ \\
\hline$Q$ & Flow rate $\left[\mathrm{m}^{3} / \mathrm{s}\right]$ \\
\hline$p$ & Fluid pressure $[\mathrm{Pa}]$ \\
\hline$p_{\text {dyn }}$ & Dynamic pressure $[\mathrm{Pa}]$ \\
\hline$p_{\text {ref }}$ & Reference pressure $[\mathrm{Pa}]$ \\
\hline$p_{\text {stat }}$ & Static pressure $[\mathrm{Pa}]$ \\
\hline$p_{\text {tot }}$ & Total pressure $[\mathrm{Pa}]$ \\
\hline$r$ & Amplitude of reflected wave [-] \\
\hline$R$ & Interphase Mass transfer rate $\left[\mathrm{kg} /\left(\mathrm{s} \mathrm{m}^{3}\right)\right]$ \\
\hline$s$ & Wall thickness $[\mathrm{m}]$ \\
\hline$t$ & Time $[\mathrm{s}]$ \\
\hline$V_{\mathrm{HR}}$ & Volume of Helmholtz resonator $\left[\mathrm{m}^{3}\right]$ \\
\hline$w$ & Flow velocity $[\mathrm{m} / \mathrm{s}]$ \\
\hline$X_{\mathrm{DA}}$ & Molar fraction of dissolved air $[-]$ \\
\hline$Z_{\mathrm{L}}$ & Impedance of the suction line $\left[\mathrm{kg} /\left(\mathrm{s} \mathrm{m}^{4}\right)\right]$ \\
\hline$Z_{\mathrm{HR}}$ & $\begin{array}{l}\text { Impedance of the Helmholtz resonator }[\mathrm{kg} / \\
\left.\left(\mathrm{s} \mathrm{m}^{4}\right)\right]\end{array}$ \\
\hline$\alpha_{1}$ & Displacement angle $\quad\left[^{\circ}\right]$ \\
\hline$\varepsilon$ & Turbulent eddy dissipation $\left[\mathrm{m}^{2} / \mathrm{s}^{3}\right]$ \\
\hline$\zeta$ & Pressure loss coefficient $\quad[-]$ \\
\hline$\eta$ & Dynamic viscosity $[\mathrm{Pa} \mathrm{s}]$ \\
\hline$\vartheta$ & Temperature $\left[{ }^{\circ} \mathrm{C}\right]$ \\
\hline$v$ & Poisson ratio $[-]$ \\
\hline$\rho$ & Density $\left[\mathrm{kg} / \mathrm{m}^{3}\right]$ \\
\hline$\varphi$ & Displacement angle $\left.\quad{ }^{\circ}\right]$ \\
\hline$\Delta p$ & Pressure amplitude or difference $[\mathrm{Pa}]$ \\
\hline$\Delta t$ & Time step size, time duration $[\mathrm{s}]$ \\
\hline$\omega$ & Turbulent eddy frequency $\left[\mathrm{s}^{-1}\right]$ \\
\hline \multicolumn{2}{|c|}{ Subscripts } \\
\hline abs & Absorption/Dissolution \\
\hline Air & Free air \\
\hline des & Desorption/Air release \\
\hline DA & Dissolved air \\
\hline Dyn & Dynamic \\
\hline equil & Equilibrium \\
\hline HR & Helmholtz resonator \\
\hline in & Incoming \\
\hline $\lim$ & Limit \\
\hline $\mathrm{L}$ & Loss \\
\hline $\min$ & Minimum \\
\hline $\operatorname{mix}$ & Mixture \\
\hline $\max$ & Maximum \\
\hline out & Outgoing \\
\hline $\mathrm{r}$ & Reflection \\
\hline stat & Static \\
\hline
\end{tabular}




$\begin{array}{ll}\text { S } & \text { Suction } \\ \text { tot } & \text { Total } \\ V & \text { Vortex } \\ B D C & \text { Bottom dead centre } \\ C F D & \text { Computational fluid dynamics } \\ C F L & \text { Courant-Friedrich-Levy } \\ F C M & \text { Full cavitation model } \\ F E M & \text { Finite element method } \\ P M M A & \text { Polymethylmethacrylat } \\ S S T & \text { Shear stress transport } \\ T D C & \text { Top dead centre }\end{array}$

\section{Acknowledgements}

We would like to thank the German Research Foundation (DFG) for funding the project "Improvement of the suction performance of axial piston pumps by means of computational fluid dynamics (CFD)" (He 2715/9-1). Furthermore we would like to thank the Fluid Power Research Fund of VDMA for their financial support of the research project "Suction line modelling of an axial piston pump considering fluid-structureinteraction" (FKM 702690).

\section{References}

Bormann, A. 2005. Elastomerringe zur Schwingungsberuhigung in der Rotordynamik - Theorie, Messungen und optimierte Auslegung. Dissertation. TU Berlin.

Bügener, N. 2014. Analyse und Verbesserung des Ansaugverhaltens von Axialkolbenpumpen in Schrägscheibenbauweise. Dissertation. Technische Universität Dresden, Institut für Fluidtechnik.

Casoli, P., Vacca, A., Franzoni, G. and Berta, G., 2006. Modelling of fluid properties in hydraulic positive displacement machines. Simulation Modelling - Practice and Theory, Vol, 14, 1059-1072.

Findeisen, D., 2006. Ölhydraulik - Handbuch für die hydrostatische Leistungsübertragung in der Fluidtechnik. Springer-Verlag.

Goenechea, E. 2007. Mechatronische Systeme zur Pulsationsminderung hydrostatischer Verdrängereinheiten. Dissertation. RWTH Aachen.

Idelchik, I.E. 2008. Handbook of Hydraulic Resistance. Jaico Publishing House. 3. Auflage.
Joukowski, N. 1898. Über den hydraulischen Stoß in Wasserleitungsröhren. Veröffentlichung der kaiserlichen Akademie der Wissenschaften. St. Petersburg.

Kiesbauer, J. 1991. Selbstanpassende Pulsationsminderer in hydraulischen Systemen, Dissertation. Technische Universität Darmstadt.

Klecker, J. and J.Weber 2013. Simulation einer kavitierenden und pulsierenden Saugströmung in einem Hydraulikschlauch. Proceedings of the ANSYS Conference \& 31. CADFEM User's Meeting, Mannheim.

Kottmann, A. 1992. Druckstoßermittlung in der Wasserversorgung.Vulkan-Verlag Essen Dissertation. Technische Universität Darmstadt

Kunze, T. 1995. Experimentelle und analytische Untersuchungen zur Kavitation bei selbstsaugenden Axialkolbenpumpen. Dissertation, TU Dresden.

Küppers, E.W.U. 2006. Entwicklung von energie (druckverlust) optimierten Bogenelementen mit nicht kreisförmigem Querschnitt nach dem Mäander-Prinzip. Abschlussbericht AZ 22301, Deutsche Bundesstiftung Umwelt.

Leonhard, A., Rüdiger, F. and Helduser, S. 2004. Flow Induced Noise in Steering Valves - Analyse and Reduction. Proceedings of the 4th Int. Fluid Power Conference (IFK), Dresden, pp. 29-40.

Lifante, C. and Frank, T. 2008. Untersuchung der Druckschwankungen höherer Ordnung am Hinterschiff unter Berücksichtigung der Kavitation am Propeller. Otterfing: Abschlussbericht.

Yang, H.Q., Singhal, A.K. and Megahed, M. 2005. Industrial two-phase flow CFD - The Full Cavitation Model. Von Karman Institute for Fluid Dynamics, Lecture Series, 2005-04.

Rechenberg, I. 1973. Evolutionsstrategie: Optimierung technischer Systeme nach Prinzipien der biologischen Evolution. Stuttgart-Bad Cannstatt: Frommann-Holzboog.

Singhal, A. K., Li, H. Y., Athavale, M.M. and Jiang, Y. 2002. Mathematical Basis and Validation of the Full Cavitation Model. ASME Journal of Fluids Engineering, 124, 617-624.

Schleihs, C., Viennet, E., Deeken, M., , Ding, H., Y.Xia, Lowry, S. and Murrenhoff, H. 2014. 3D-CFD simulation of an axial piston displacement unit. Proceedings of the 9th Int. Fluid Power Conference (IFK), Aachen, Vol. 3, pp. 332-343.

Wustmann, W. 2010. Experimentelle und numerische Untersuchung der Strömungsvorgänge in hydrostatischen Verdrängereinheiten am Beispiel von Außenzahnrad- und Axialkolbenpumpen. Dissertation. Technische Universität Dresden, Institut für Fluidtechnik. 